\title{
The Effects of an Advanced Movable Restraint Design on the Elderly Residents at Long-Term Care Facilities in Taiwan
}

\author{
Meng-Ping Wu, (Doctoral Candidate and RN, Deputy Director) \\ School of Nursing, National Taipei University of Nursing and Health \\ Sciences Department of Nursing, Taipei City Hospital \\ Lee-Ing Tsao, (DNS, RN, Professor)
}

School of Nursing, National Taipei University of Nursing and Health

Sciences

Doi: 10.19044/esj.2018.v14n33p104 URL:http://dx.doi.org/10.19044/esj.2018.v14n33p104

\begin{abstract}
Purpose: The purpose of this study was to evaluate the effects, both initially and after 6 months, of an "advanced movable restraint" with openended palm sleeve restraint bands for the elderly residents at long-term care facilities in northern Taiwan. Background. Elderly residents in long-term care facilities are often forced to remain bed-ridden by traditional bed restraint bands due to their irritable, confused conditions and the associated risks of self-extubating their nasogastric (NG) tubes, urinary catheters, etc. However, the traditional bed restraint bands can themselves lead to further physical and mental complications such as skin damage, depression, hostility, and even rhabdomyolysis, increasing the risk of death. Design. Quasiexperimental design. Methods: This parallel-design study was conducted with elderly residents at eight long-term care facilities. The newly designed advanced movable restraint featuring movable open-ended palm sleeve restraint bands was applied to the elderly residents in the experimental group, allowing them greater freedom of movement such that they were not required to remain bed-ridden. In contrast, the elderly residents in the control group were restrained with traditional bed restraints requiring that they remain bedridden. The following four instruments and indicators were then used to compare the effects of the two types of restraints: (1) an activities of daily living (ADL) survey based on the Barthel Index, (2) a muscle power test, (3) an exercise frequency and duration survey, and (4) self-extubation rates. The effects of the interventions were tested by using the $t$ test or chi-square test to compare pre-test results for the ADL survey, muscle power test, exercise frequency and duration survey, and self-extubation rates to those at a 6-month follow-up. Results: A total of 80 elderly residents were included in the
\end{abstract}


experimental group, while 80 elderly residents were included in the control group. At the 6-month follow-up, the residents restrained with the advanced movable restraint had a significantly increased mean muscle power score $(\chi 2$ $=17.212, \mathrm{P}<0.001)$, significantly decreased self-extubation rate $\left(\chi^{2}=40.733\right.$, $\mathrm{P}<.001)$, and significantly increased exercise frequency and duration per week $(\chi 2=27.095 \mathrm{P}<0.001 ; 26.241 \mathrm{P}<0.001)$. Conclusions: This study showed that the advanced movable restraint can improve muscle power scores, self-extubation rates, and exercise frequencies and durations by allowing residents greater freedom of movement without the need to remain bed-ridden. It is thus crucial to use such advanced movable restraints and develop standardized technology systems to support the elderly residents and nurses in long-term care facilities.

Keywords: Restraint, long-term care facilities, self-extubation

\section{Introduction}

Patients' restless behaviors are a common reason for using physical restraints (Luk, Burry, Rezaie, Mehta, \& Rose, 2015). Nurses apply restraints to patients mainly in order to prevent injuries. However, clinical research has indicated that restraints cannot prevent patients from falling or reduce the need for nursing personnel (Hamers \& Huizing, 2005). Meanwhile, bedsores that occur during the application of invasive tubes, such as nasogastric and urinary catheters, are significantly correlated with the use of restraints (Raguan, Wolfovitz, \& Gil, 2015). Limited movement and reduced interaction with the external world cause such complications as sensory disturbances, reduced ranges of activity, variations in muscle strength, and urinary and fecal incontinence, and may even lead to death in severe cases (Stinson, 2016; Eskandari, Abdullah, Zainal, \& Wong, 2018). The use of physical restraints leads to poorer cognitive and activities of daily living (ADL) performance and higher dependence in daily life, and increases the likelihood of falls, pressure sores, and urinary and fecal incontinence (Stinson, 2016; Hofmann \& Hahn, 2014). In addition, restraints increase the risk of falls, injuries, and death. A comprehensive overview of modern longterm care institutions shows that most of such facilities focus on making improvements to restraint straps, the rationalization of restraints, and the acquisition of consent from families. Little attention is paid, however, to the planning and design of a restraint-free care environments. Older adults are known to lose muscle mass, strength, and physical functions with age ( $\mathrm{Ni}$ Lochlainn et al., 2018), with 14-33\% of older adults receiving long-term care suffering from sarcopenia. Such data suggests that exercise interventions could improve muscle strength and physical performance (Cruz-Jentoft et al., 2014). Meanwhile, a study from Australia showed that restraints often 
constitute a last resort for nurses seeking to ensure patient safety as their use can deprive nurses of resources and reduce empathy and friendly relations between nurses and patients (Gerace \& Muir-Cochrane, 2018).

The percentage of inpatients to whom physical restraints are applied in Taiwan has reached as high as $46.6 \%$ (Huang et al., 2005). Relatedly, despite the growing attention paid to restraint usage and improvements in restraint evaluations, the ethical knowledge of healthcare providers is rarely considered (Kor, Kwan, Liu, \& Lai, 2018). In Europe and America, special educational courses aimed at the construction of non-restrained long-term care environments and the reduction of the use of physical restraints by nurses have been conducted for many years, providing a reference for restraint policies in Taiwanese long-term care institutions and effectively reducing the rate at which restraints are applied to inpatients (Huang et al., 2005). Physical restraints are used to improve patients' safety and prevent injuries. If applied incorrectly or without continuous monitoring, however, physical restraints can cause injuries. Nurses who apply physical restraints often lack relevant knowledge, which increases the associated risks to patients' safety (Chang, Yu, Loh, \& Chang, 2016).

It is crucial for long-term care health providers to develop and utilize restraint devices that allow for greater freedom of movement in order to protect the health of elderly residents and maintain friendly relationships between such residents and their healthcare providers. To that end, the purpose of the current study was to evaluate the effects of an "advanced movable restraint" featuring movable open-ended palm sleeves on the ADLs, muscle power, exercise frequency and duration, and unplanned extubation rates among elderly residents of long-term care facilities after 6 months of use.

\section{Methods}

\section{Research Design}

This parallel-design study was conducted at eight long-term care facilities for elderly residents in Taipei City. All the elderly residents at the facilities treated with physical restraint bands were recruited. After consent was obtained from the persons in charge of the care facilities and the residents or their families, each resident was assigned to either the experimental group or the control group. Each group included 80 participants, so the total number of participants amounted to 160 people. 


\begin{tabular}{|c|c|c|c|c|c|c|}
\hline $\begin{array}{l}\text { Research } \\
\text { design }\end{array}$ & Groups & & Pre-test $\longrightarrow$ & $\begin{array}{l}\text { Intervention } \\
\text { (six months) }\end{array}$ & $\longrightarrow$ & Post-test \\
\hline $\begin{array}{l}\text { Quasi- } \\
\text { experimental } \\
\text { design }\end{array}$ & $\begin{array}{l}\text { Experimental group } \\
\qquad(\mathrm{n}=80)\end{array}$ & 3. & $\begin{array}{l}\text { Barthel } \\
\text { Index } \\
\text { muscle } \\
\text { power score } \\
\text { exercise } \\
\text { frequency } \\
\text { and } \\
\text { duration } \\
\text { self- } \\
\text { extubation } \\
\text { rate }\end{array}$ & $\begin{array}{c}\text { Advanced Movable } \\
\text { Restraint }\end{array}$ & 2. & $\begin{array}{l}\text { Barthel } \\
\text { Index } \\
\text { muscle } \\
\text { power } \\
\text { score } \\
\text { exercise } \\
\text { frequenc } \\
\text { y and } \\
\text { duration } \\
\text { self- } \\
\text { extubation } \\
\text { rate }\end{array}$ \\
\hline
\end{tabular}

Figure 1. Research design

\section{Participants}

The participants had to meet the following inclusion criteria: (1) home care patients as defined by the National Health Insurance Administration: level 3-4 on Karnofsky scale, 60 points or lower on Barthel Index , clear consciousness for more than $50 \%$ of time, activity limited to bed or chair. (2) Intubation, including nasogastric tubes and urinary tubes; duration of restraint not exceeding three months. (3) Consent to participate in the study. The researchers recorded information regarding self-extubation and related limb movements in the patients.

\section{Intervention}

The design of the study included specific activities undertaken prior to, during, and after the experiment.

1. Prior to the experiment: Under the assumptions of the study design, the degree of restraint had to be minimized during the use of restraints while still adhering to the principle of maximum safety (Liao, Chang, $\& \mathrm{Li}, 2015)$. To that end, the research team designed a new advanced movable restraint featuring movable open-ended palm sleeve restraint bands. This design was audited as a utility model patent (NO: 107210953) by the Taiwan Intellectual Property Office. The use of creative and feasible therapies stimulates the cranial nerves of older adults and enhances their interactivity. With regard to the design of restraints in particular, the use of traditional Taiwanese totems and ornamental colors helps to recall older adults' memories through sensory stimulation. The special advanced movable restraint produced for this study was produced using empty plastic bottles. The restraint allows adequate air circulation, allows the fingers to move freely, and 
does not constrain the limbs. Foam protection placed around the patient's wrists prevents skin damage and edema caused by restlessness and hindrance and reduces the incidence of restraintrelated complications. As such, the restraint compensates for the disadvantages of the traditional restraint and can provide better effects. After designing and producing the advanced movable restraint, the researchers trained three home nurses on how to apply the new movable restraint, and these nurses completed the reply demonstration. In addition, pre-test data was gathered for all the elderly resident participants, including demographic data, ADL scores based on the Barthel Index, muscle power scores, exercise frequencies and durations, and the unplanned extubation rate.

2. During the experiment: Using a standard intervention design, the researcher and the trained home nurses visited eight 35-bed elderly long-term care facilities with the same ranking level, and guided the workers at the institutions on how to use the new restraint. Residents at four of the eight long-term care facilities were then assigned to the experimental group, and residents at the other four facilities were assigned to the control group. The residents in the experimental group wore the new restraint devices instead of using traditional restraint bands that would require them to remain bed-ridden. The experimental group residents were encouraged to ambulate at their will. The trained home nurses visited the institutions every 2 weeks to understand their actual use of the new restraint devices and to guide the caregivers on restraint-related care issues; relatedly, free phone consultations were also provided as necessary. The control group was uniformly assisted by a home nurse to collect data, and the residents were observed in using the traditional bed rail restraints and performing related activities in accordance with the usual work procedures.

3. At 6 months after the intervention: the home nurses collected post-test data for all the elderly residents.

\section{Research Tools and Data Analysis}

The questionnaire measured basic variables using the older adults' basic data, Barthel Index, limb activity, and the Karnofsky scale. Other variables included a muscle power score, self-extubation frequency, frequency of exercise each week, and duration of exercise each week. With regard to design, traditional Taiwanese totems and ornamental colors were used in the design of the advanced restraint to help the older adults' to recall memories through sensory stimulation, while a bell mechanism was used to stimulate the cranial nerves of the older adults. A special advanced movable 
restraint was produced using empty plastic bottles. Data was analyzed using descriptive statistics, including frequency distributions, percentages, mean values, standard deviations, the chi-squared test, and the t-test.

\section{Results}

After the advanced movable restraint was used on the experimental group, it was found that the participants in the experimental group exhibited a higher activity level (e.g. regular exercise, weekly exercise frequency, number of hours per exercise session) compared to the control group. Also, fewer participants in the experimental group had experienced self-extubation compared to the control group, and among those who did, the number of participants who experienced self-extubation three or more times was also lower compared to the control group. Furthermore, a greater number of participants from the experimental group had achieved a muscle power score of 2 points or higher compared to the control group. These findings indicated that the participants who received the intervention significantly outperformed those who did not in terms of muscle power score, activity level, and number of self-extubation. However, no significant differences between the two groups were observed with respect to their Barthel Index, indicating that the advanced movable restraint had no significant effects on the Barthel Index of the participants.

\section{Demographic Information}

A total of 160 residents living in elderly care institutions were recruited for this study. The participants were assigned via convenience sampling to the experimental $(\mathrm{N}=80)$ and control $(\mathrm{N}=80)$ groups. There were no significant differences (Tables 1-1 and 1-2) between the experimental and control groups in terms of gender, age, height, weight, blood pressure, education, religious beliefs, family companionship, regular physician visits, Karnofsky grade, Barthel Index scores, or chronic diseases (e.g. high blood pressure, diabetes, hyperlipidemia, heart disease, asthma, hyperuricemia, kidney disease, anemia, stroke, and cancer). Before the advanced movable restraint was used as an intervention, the two groups were demographically homogeneous. Of the 160 participants in this study, 46 male and 34 female participants were assigned to the experimental group, in which the mean age, height, and weight were $80.2 \pm 9.9,157.4 \pm 12.9 \mathrm{~cm}$, and $54.9 \pm 9.5 \mathrm{~kg}$, respectively. The largest percentages of the participants in this group were illiterate (35 participants, 43.8\%), Buddhists (44 participants, 55\%), married (88 participants, 55\%), and of Minnan descent (88 participants, 55\%). Furthermore, most of them did not have access to family companionship (65 participants, $81.3 \%$ ) and had been residents for 1-3 years (34 participants, 42.5\%) (Table 1-1). 
41 male $(51.3 \%)$ and 39 female $(48.8 \%)$ participants were assigned to the control group, in which the mean age, height, and weight were 80.6 \pm 9.3 , $157.5 \pm 8.0 \mathrm{~cm}$, and $52.5 \pm 8.3 \mathrm{~kg}$, respectively. The largest percentages of the participants in this group were elementary school-educated (33 participants, 41.3\%), Buddhists (34 participants, 42.5\%), widowed (13 participants, 65\%), and of Mainland Chinese (waishengren) descent (96 participants, 60\%). Furthermore, most of them did not have access to family companionship (61 participants, 76.3\%) and had been residents for 1-3 years (30 participants, $37.5 \%)$.

The above information indicated that most of the 160 residents were elderly individuals, Buddhists, individuals who did not have access to family companionship, and individuals who had been residents for 1-3 years. With regard to pretest Barthel Index scores, the experimental and control groups had mean scores of $1.13 \pm 3.64$ and $1.75 \pm 5.16$, respectively, indicating that there was no significant difference between the two groups in this area (Table 1-1).

Table 1. Baseline characteristics of participants $(\mathrm{N}=160)$

\begin{tabular}{|c|c|c|c|c|c|}
\hline Item & $\begin{array}{c}\text { Experimental group (\%) } \\
(\mathbf{n}=\mathbf{8 0})\end{array}$ & $\begin{array}{c}\text { Control group }(\%)(n= \\
80)\end{array}$ & $\begin{array}{c}\text { Total } \\
(\mathrm{N}=160)\end{array}$ & $\mathbf{X} 2 / \mathrm{t}$ & $\mathbf{P}$ \\
\hline \multicolumn{6}{|l|}{ Gender } \\
\hline Male & $46(57.5)$ & $41(51.3)$ & $87(54.4)$ & 0.63 & 0.427 \\
\hline Female & $34(42.5)$ & $39(48.8)$ & $73(45.6)$ & & (NS) \\
\hline Age $(\mathrm{M} \pm \mathrm{SD})$ & $80.2 \pm 9.9$ & $80.6+9.3$ & $80.4 \pm 9.6$ & & \\
\hline Height ( $\overline{\mathbf{M}}+\mathbf{S D})$ & $157.4 \pm 12.9$ & $157.5 \pm 8.0$ & $157.4 \pm 10.7$ & 0.255 & 0.799 \\
\hline Weight (M+SD) & $54.9 \pm 9.5$ & $52.5+8.3$ & $53.7 \pm 9.0$ & 0.049 & 0.961 \\
\hline Blood pressure & & & & -1.695 & 0.092 \\
\hline $\begin{array}{r}\text { Systolic blood pressure } \\
(\mathrm{M}+\mathrm{SD})\end{array}$ & $124.9 \pm 12.9$ & $127.9 \pm 13.8$ & $126.4 \pm 13.4$ & & \\
\hline $\begin{array}{r}\text { Diastolic blood pressure } \\
(\mathrm{M}+\mathrm{SD})\end{array}$ & $73.2+7.8$ & $72.6 \pm 10.2$ & $72.9+9.1$ & 1.39 & 0.166 \\
\hline Education Level & & & & -0.468 & 0.641 \\
\hline Illiterate & $35(43.8)$ & $25(31.3)$ & $60(37.5)$ & 2.72 & 0.437 \\
\hline Elementary school & $27(33.8)$ & $33(41.3)$ & $60(37.5)$ & & \\
\hline Junior high school & $10(12.5)$ & $13(16.3)$ & $23(14.4)$ & & \\
\hline $\begin{array}{r}\text { Senior/vocational high } \\
\text { school or higher }\end{array}$ & $8(10)$ & $9(11.3)$ & $17(10.6)$ & & \\
\hline \multicolumn{6}{|l|}{ Religion } \\
\hline None & $16(20.0)$ & $20(25.0)$ & $36(22.5)$ & 2.85 & 0.415 \\
\hline Buddhist & $44(55.0)$ & $34(42.5)$ & $78(48.8)$ & & \\
\hline Taoist & $13(16.3)$ & $19(23.8)$ & $32(20.0)$ & & \\
\hline $\begin{array}{r}\text { Protestant or Catholic } \\
\text { Christian }\end{array}$ & $7(8.8)$ & $7(8.8)$ & $14(8.8)$ & & \\
\hline \multicolumn{6}{|l|}{ Family companionship } \\
\hline Yes & $65(81.3)$ & $61(76.3)$ & $126(78.8)$ & 0.598 & 0.440 \\
\hline No & $15(18.8)$ & $19(23.8)$ & $34(21.3)$ & & \\
\hline \multicolumn{6}{|l|}{ Regular physician visits } \\
\hline Yes & $3(3.8)$ & $0(0)$ & $3(1.9)$ & 3.057 & $0.245^{\mathrm{c}}$ \\
\hline No & $77(96.3)$ & $80(100.0)$ & $157(98.1)$ & & \\
\hline \multicolumn{6}{|l|}{ Karnofsky Scale } \\
\hline 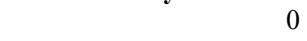 & $0(0)$ & $0(0)$ & $0(0)$ & 1.653 & 0.199 \\
\hline 1 & $0(0)$ & $0(0)$ & $0(0)$ & & \\
\hline 2 & $0(0)$ & $0(0)$ & $0(0)$ & & \\
\hline 3 & $16(20.0)$ & $10(12.5)$ & $26(16.3)$ & & \\
\hline 4 & $64(80.0)$ & $70(87.5)$ & $134(83.8)$ & & \\
\hline Barthel Index (M+SD) & $1.13+3.64$ & $1.75+5.16$ & $1.44+4.47$ & 0.885 & 0.378 \\
\hline
\end{tabular}




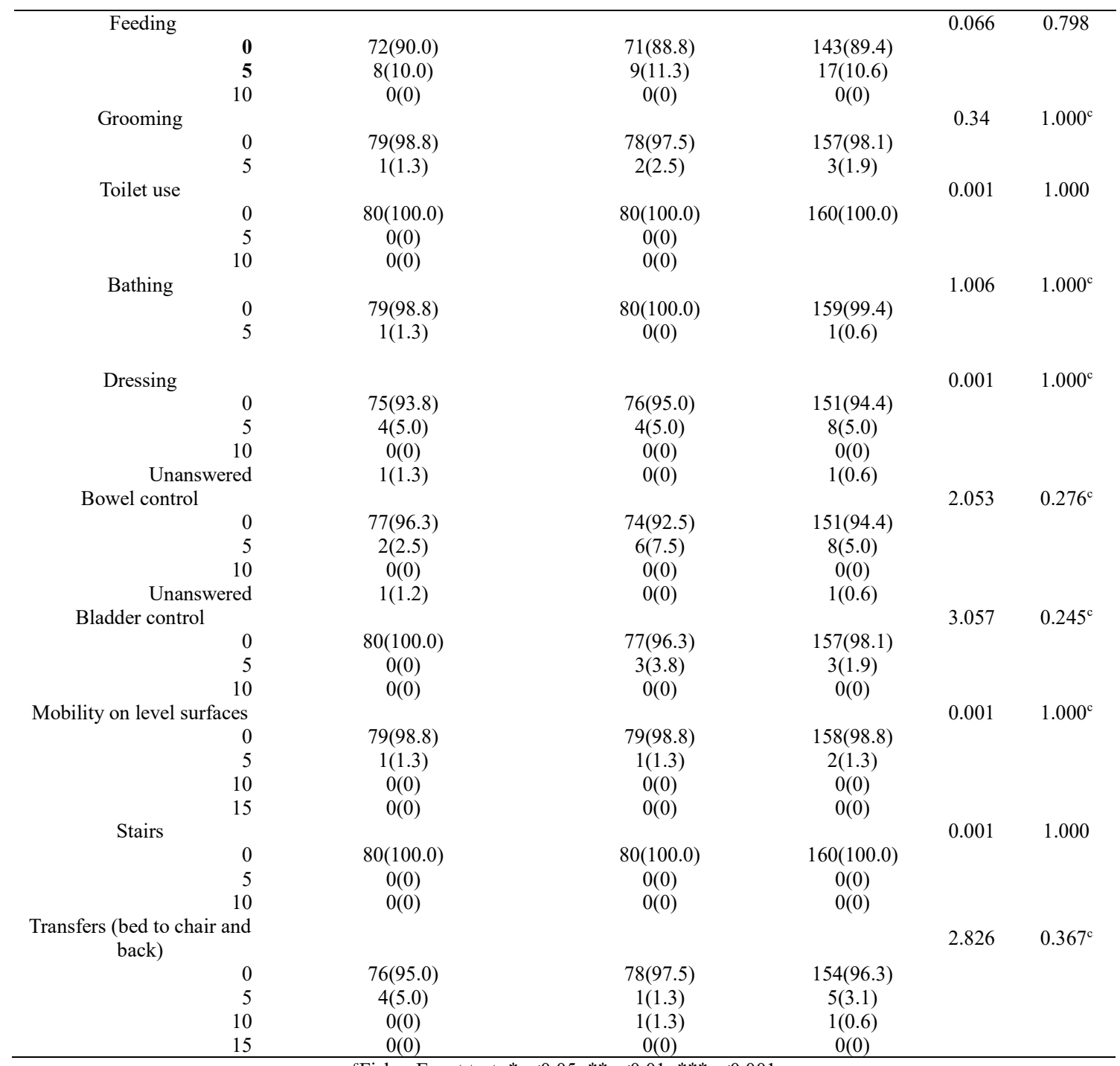

${ }^{\mathrm{c}}$ Fisher Exact test; ${ }^{*} \mathrm{p}<0.05 ; * * \mathrm{p}<0.01 ; * * * \mathrm{p}<0.001$

Table 2. The comparison of the effects between experimental and control groups

\begin{tabular}{|c|c|c|c|c|c|}
\hline Item & $\begin{array}{c}\text { Experimental group (\%) (n } \\
=80)\end{array}$ & $\begin{array}{l}\text { Control group (\%) }(\mathrm{n}= \\
\text { 80) }\end{array}$ & $\begin{array}{c}\text { Total } \\
(\mathrm{N}=160)\end{array}$ & $\mathrm{X2} / \mathrm{t}$ & $\mathbf{P}$ \\
\hline \multirow{2}{*}{$\begin{array}{l}\text { Barthel Index (M+SD) } \\
\text { Feeding }\end{array}$} & $0.95 \pm 3.59$ & $1.81 \pm 5.29$ & $1.38+4.53$ & 1.226 & 0.222 \\
\hline & & & & 0.278 & 0.598 \\
\hline & 73(91.3) & $71(88.8)$ & 144(90.0) & & \\
\hline & $7(8.8)$ & $9(11.3)$ & $16(10.0)$ & & \\
\hline & $0(0)$ & $0(0)$ & $0(0)$ & & \\
\hline \multirow[t]{3}{*}{ Grooming } & & & & 0.34 & $1.000^{\circ}$ \\
\hline & $79(98.8)$ & $78(97.5)$ & $157(98.1)$ & & \\
\hline & $1(1.3)$ & $2(2.5)$ & 3(1.9) & & \\
\hline \multirow[t]{3}{*}{ Toilet use } & & & & 0.001 & 1.000 \\
\hline & $80(100.0)$ & $80(100.0)$ & $160(100.0)$ & & \\
\hline & $0(0)$ & $0(0)$ & $0(0)$ & & \\
\hline \multirow[b]{2}{*}{ Bathing } & $0(0)$ & $0(0)$ & $0(0)$ & & \\
\hline & & & & 1.006 & $1.000^{\mathrm{c}}$ \\
\hline
\end{tabular}




\begin{tabular}{|c|c|c|c|c|c|}
\hline 5 & $1(1.3)$ & $0(0)$ & $1(0.6)$ & & \\
\hline Dressing & & & & 0.526 & $0.719^{\mathrm{c}}$ \\
\hline 0 & $77(96.3)$ & $75(93.8)$ & $152(95.0)$ & & \\
\hline 5 & $3(3.8)$ & $5(6.3)$ & $8(5.0)$ & & \\
\hline 10 & $0(0)$ & $0(0)$ & $0(0)$ & & \\
\hline Bowel control & & & & 3.671 & $0.117^{\mathrm{c}}$ \\
\hline 0 & $78(97.5)$ & $74(92.5)$ & $152(95.0)$ & & \\
\hline 5 & $1(1.3)$ & $6(7.5)$ & $7(4.4)$ & & \\
\hline 10 & $0(0)$ & $0(0)$ & $0(0)$ & & \\
\hline Unanswered & $1(1.3)$ & $0(0)$ & $1(0.6)$ & & \\
\hline Bladder control & & & & 3.057 & $0.245^{\mathrm{c}}$ \\
\hline 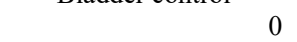 & $80(100.0)$ & $77(96.3)$ & $157(98.1)$ & & \\
\hline 5 & $0(0)$ & $3(3.8)$ & $3(1.9)$ & & \\
\hline 10 & $0(0)$ & $0(0)$ & $0(0)$ & & \\
\hline $\begin{array}{l}\text { Mobility on level } \\
\text { surfaces }\end{array}$ & & & & 0.001 & $1.000^{\mathrm{c}}$ \\
\hline surtaces & $79(98.8)$ & $79(98.8)$ & $158(98.8)$ & & \\
\hline 5 & $1(1.3)$ & $1(1.3)$ & $2(1.3)$ & & \\
\hline 10 & $0(0)$ & $0(0)$ & $0(0)$ & & \\
\hline 15 & $0(0)$ & $0(0)$ & $0(0)$ & & \\
\hline Stairs & & & & 0.001 & 1.000 \\
\hline 0 & $80(100.0)$ & $80(100.0)$ & $160(100.0)$ & & \\
\hline 5 & $0(0)$ & $0(0)$ & $0(0)$ & & \\
\hline 10 & $0(0)$ & $0(0)$ & $0(0)$ & & \\
\hline $\begin{array}{l}\text { Transfers (bed to chair } \\
\text { and back) }\end{array}$ & & & & 2.006 & $0.620^{\mathrm{c}}$ \\
\hline 0 & $77(96.3)$ & $78(97.5)$ & $155(96.9)$ & & \\
\hline 5 & $3(3.8)$ & $1(1.3)$ & $4(2.5)$ & & \\
\hline 10 & $0(0)$ & $1(1.3)$ & $1(0.6)$ & & \\
\hline 15 & $0(0)$ & $0(0)$ & $0(0)$ & & \\
\hline Regular exercise & & & & 12.168 & $<.001^{* *}$ \\
\hline No & $26(32.5)$ & $48(60.0)$ & $74(46.3)$ & & \\
\hline Yes & $54(67.5)$ & $32(40.0)$ & $86(53.8)$ & & \\
\hline $\begin{array}{l}\text { Weekly exercise } \\
\text { frequency }\end{array}$ & & & & 27.095 & $<.001^{* *}$ \\
\hline Does not exercise & $9(11.3)$ & $37(46.3)$ & $46(28.8)$ & & \\
\hline 1-2 times & $18(22.5)$ & $18(22.5)$ & $36(22.5)$ & & \\
\hline 3 times or more & $53(66.3)$ & $25(31.3)$ & $78(48.8)$ & & \\
\hline $\begin{array}{l}\text { Number of hours spent } \\
\text { per exercise session }\end{array}$ & & & & 26.241 & $<. .001^{* *}$ \\
\hline Does not exercise & $8(10.0)$ & $37(46.3)$ & $45(28.1)$ & & \\
\hline $\begin{array}{r}\text { Between } 0.5 \text { and }<1 \\
\text { hour }\end{array}$ & $65(81.3)$ & $40(50.0)$ & $105(65.6)$ & & \\
\hline 1 hour or more & $7(8.8)$ & $3(3.8)$ & $10(6.3)$ & & \\
\hline $\begin{array}{l}\text { Number of self- } \\
\text { extubations over the } \\
\text { last six months }\end{array}$ & & & & 40.733 & $<\underset{{ }_{*_{c}}}{.001^{* *}}$ \\
\hline 0 & $64(80.0)$ & $30(37.5)$ & $94(58.8)$ & & \\
\hline $1-2$ & $13(16.3)$ & $13(16.3)$ & $26(16.3)$ & & \\
\hline $3-4$ & $3(3.8)$ & $22(27.5)$ & $25(15.6)$ & & \\
\hline 5 or more & $0(0)$ & $14(17.5)$ & $14(8.8)$ & & \\
\hline Unanswered & $0(0)$ & $1(1.3)$ & $1(0.6)$ & & \\
\hline Muscle power score & & & & 17.212 & $<.001^{* *}$ \\
\hline 0 & $0(0)$ & $14(17.5)$ & $14(8.8)$ & & \\
\hline 1 & $21(26.3)$ & $23(28.8)$ & $44(27.5)$ & & \\
\hline 2 & $32(40.0)$ & $20(25.0)$ & $52(32.5)$ & & \\
\hline 3 & $23(28.8)$ & $20(25.0)$ & $43(26.9)$ & & \\
\hline 4 & $4(5.0)$ & $3(3.8)$ & $7(4.4)$ & & \\
\hline
\end{tabular}


With regard to the clinical benefits evaluation of the use of the advanced movable restraint on the participants (Tables 2), the following results were obtained: In terms of the participants' regular exercise habits, a statistically significant post-intervention difference $(\chi 2=12.168, \mathrm{p}<.001)$ was observed between the two groups. In the experimental group, 54 participants $(67.5 \%)$ exercised regularly, while 16 participants $(32.5 \%)$ did not do so; and in the control group, 32 participants $(40 \%)$ exercised regularly, while 48 participants $(60 \%)$ did not do so. This indicated that, after the intervention, the experimental group had more participants who engaged in regular exercise than the control group. In terms of weekly exercise frequency, a statistically significant post-intervention difference $(\chi 2=27.095, \mathrm{p}<.001)$ was observed between the two groups. In the experimental group, 9 participants $(11.3 \%)$ did not engage in exercise, 18 participants (22.5\%) exercised 1-2 times weekly, and 53 participants $(66.3 \%)$ exercised 3 times or more weekly; and in the control group, 37 participants $(46.3 \%)$ did not engage in exercise, 18 participants $(22.5 \%)$ exercised $1-2$ times weekly, and 25 participants $(31.3 \%)$ exercised 3 times or more weekly. This indicated that, after the intervention, the experimental group had more participants who exercised weekly than the control group. In terms of the number of hours spent per exercise session, a statistically significant post-intervention difference $(\chi 2=26.241, \mathrm{p}<.001)$ was observed between the two groups. In the experimental group, 8 participants $(10.0 \%)$ did not engage in exercise, 65 participants $(81.3 \%)$ exercised between 0.5 hour and less than 1 hour per exercise session, and 7 participants $(8.8 \%)$ exercised for 1 hour or more per exercise session; and in the control group, 37 participants $(46.3 \%)$ did not engage in exercise, 40 participants $(50.0 \%)$ exercised between 0.5 hour and less than 1 hour per exercise session, and 3 participants $(3.8 \%)$ exercised for 1 hour or more per exercise session; and in the control group. This indicated that, after the intervention, the experimental group had more participants who exercised for 0.5 hours or more than the control group. The above findings showed that there were statistically significant differences in the activity level of the experimental and control groups after the intervention, with the experimental group having a higher activity frequency than the control group.

In terms of the number of self-extubations that occurred over the preceding six months, a statistically significant post-intervention difference $(\chi 2=40.733, \mathrm{p}<.001)$ was observed between the two groups. In the experimental group, 64 participants $(80.0 \%)$ did not experience any selfextubations, 13 participants (16.3\%) experienced 1-2 self-extubations, and 3 participants (3.8\%) experienced 3-4 self-extubations; and in the control group, 30 participants $(37.5 \%)$ did not experience any self-extubations, 13 participants (16.3\%) experienced 1-2 self-extubations, 22 participants $(27.5 \%)$ experienced 3-4 self-extubations, 14 participants (17.5\%) experienced 5 or 
more self-extubations, and 1 participant (1.3\%) did not answer the question. This indicated that, after the intervention, the experimental group had more participants who did not experience any self-extubations over the preceding six months than the control group, as well as fewer participants who experienced 3 or more self-extubations than the control group.

In terms of muscle power, a statistically significant post-intervention difference $(\chi 2=17.212, \mathrm{p}<.001)$ was observed between the two groups. In the experimental group, 21 participants $(26.3 \%)$ obtained a muscle power score of 1 point, 32 participants $(40.0 \%)$ obtained a muscle power score of 2 points, 23 participants $(28.8 \%)$ obtained a muscle power score of 3 points, 4 participants $(5.0 \%)$ obtained a muscle power score of 4 points; and in the control group, 14 participants $(17.5 \%)$ obtained a score of 0 points, 23 participants $(28.8 \%)$ obtained a muscle power score of 1 point, 20 participants $(25.0 \%)$ obtained a muscle power score of 2 points, 20 participants $(25.0 \%)$ obtained a muscle power score of 3 points, 3 participants (3.8\%) obtained a muscle power score of 4 points. This indicated that, after the intervention, the experimental group had more participants who obtained a muscle power score of 2 points or higher than the control group.

In terms of ADL functions, no statistically significant differences were observed between the experimental and control groups with respect to feeding $(\chi 2=.278, \mathrm{p}=.598)$, grooming $(\chi 2=.34, \mathrm{p}=1.000)$, toilet use $(\chi 2=.001, \mathrm{p}=$ 1.000), bathing $(\chi 2=1.006, \mathrm{p}=1.000)$, dressing $(\chi 2=.526, \mathrm{p}=.719)$, bowel control $(\chi 2=3.671, \mathrm{p}=.117)$, bladder control $(\chi 2=3.057, \mathrm{p}=.245)$, mobility on level surfaces $(\chi 2=.001, \mathrm{p}=1.000)$, stair mobility $(\chi 2=.001, \mathrm{p}=1.000)$, and transfers (bed to chair and back) $(\chi 2=2.006, \mathrm{p}=.620)$. There was no significant difference $(\mathrm{t}=1.226, \mathrm{p}=.222)$ in the overall score for ADL functions between the two groups, indicating that the two groups' ability to perform ADLs did not change significantly after the invervention.

\section{Discussion}

This study examined the use of the advanced movable restraint on study participants. Basic data about the experimental and control groups were collected and analyzed. A further statistical analysis was then performed to examine the participants' posttest results (six months after the intervention) for muscle power, number of self-extubations, weekly exercise frequency, and number of hours spent per exercise session. The results indicated that, six months after the intervention, there was a statistically significant difference $(\chi 2=17.212, p<.001)$ in muscle power between the two groups. Significant differences in the number of self-extubations, weekly exercise frequency, number of hours spent per exercise session, and exercise regularity were also observed between the two groups $(\mathrm{p}<.001)$. Therefore, the use of the advanced movable restraint can help residents to avoid risks (such as low cognition the 
loss of independence in ADL) that result from the use of physical restriants (Hofmann \& Hahn, 2014), and can significantly reduce the occurrence of comorbidities (such as perceptual deprivation, reduced activity range, decreased muscle strength, and bowel and bladder incontinence) caused by the reduction in interactions with the outside world that physically restrained residents have to deal with (Eskandari et al., 2018). The findings also indicated that the advanced movable restraint can effectively reduce the accidental selfextubation rate for nasogastric tubes and urinary catheters, and increase the frequency and length of exercise for residents receiving institutional care, which will help to reduce limb atrophy in a clinical environment. To achieve the above effects, innovative measures must be implemented to ensure that nursing staff maintain safe practices, and practical guidelines must be developed to minimize the use of physical restraints whenever possible (Gerace \& Muir-Cochrane, 2018). Regardless of the level of physical and psychological autonomy possessed by an elderly individual, he or she would still desire happiness and respect. For elderly individuals with significantly reduced self-care ability, long-term care systems should provide care and support in such a way that their fundamental rights, fundamental freedoms and human dignity are protected, and furthermore, this can also reduce the improper use of acute care services (WHO, 2018). It is thus necessary to enhance the knowledge, skills, and attitudes of nursing staff with respect to physical restraints (Eskandari et al., 2018), and to provide a reference for longterm care facilities and clinical care personnel.

\section{Conclusion}

After the advanced movable restraint was used, the participants from the experimental group were observed to have: higher activity levels (for items such as exercise regularity, weekly exercise frequency, and number of hours spent per exercise session); a higher number of participants who did not experience any self-extubations; a lower number of participants who experienced 3 or more self-extubations; and a higher number of participants who achieved a muscle power score of 2 or higher. These findings showed that, in terms of muscle power score, activity level, and the number of selfextubations experienced, there were significant differences between the participants who received the intervention and those who did not.

\section{Limitations}

Limitations of the study: Due to time, human resource, and material constraints, the study participants consisted only of residents living in elderly care institutions that were located in Taipei City and had 30 or more beds. A pretest-posttest quasi-experimental design was utilized to collect and analyze the data generated by the 160 participants. 


\section{Recommendations}

It is crucial to use advanced movable restraints and develop standardized technology systems to support the elderly residents and nurses in long-term care facilities.

\section{References:}

1. Chang, Y. Y., Yu, H. H., Loh, el-W., \& Chang, L. Y. (2016). The Efficacy of an In-Service Education Program Designed to Enhance the Effectiveness of Physical Restraints. Journal of Nursing Research, 24(1), 79-86. doi: 10.1097/jnr.0000000000000092

2. Cruz-Jentoft, A. J., Landi, F., Schneider, S. M., Zúñiga, C., Arai, H., Boirie, Y., ... \& Sieber, C. (2014). Prevalence of and interventions for sarcopenia in ageing adults: a systematic review. Report of the International Sarcopenia Initiative (EWGSOP and IWGS). Age and Ageing, 43(6), 748-759. doi:10.1093/ageing/afu115

3. Eskandari, F., Abdullah, K. L., Zainal, N. Z., \& Wong, L. P. (2018). The effect of educational intervention on nurses' knowledge, attitude, intention, practice and incidence rate of physical restraint use. Nurse Education in Practice, 32, 52-57. doi: 10.1016/j.nepr.2018.07.007

4. Gerace, A., \& Muir-Cochrane, E. (2018). Perceptions of nurses working with psychiatric consumers regarding the elimination of seclusion and restraint in psychiatric inpatient settings and emergency departments: An Australian survey. International Journal of Mental Health Nursing. doi: 10.1111/inm.12522

5. Hamers, J.P.H. \& Huizing, A.R. Z (2005) Why do we use physical restraints

6. in the elderly? Zeitschrift für Gerontologie und Geriatrie , 38(1), 19 25. doi:10.1007/s00391-005-0286-x

7. Hofmann, H., \& Hahn, S. (2014). Characteristics of nursing home residents and physical restraint: a systematic literature review. Journal of Clinical Nursing, 23(21-22), 3012-3024. doi: 10.1111/jocn.12384

8. Huang, H. T., Chuang, Y. H., Chen, C. Y., Lee, B. O., \& Lin, P. C. (2005). Perceptions of Physical Restraints among the Hospitalized Elderly. Journal of Evidence-Based Nursing, 1(2), 123-131. doi:10.6225/JEBN.1.2.123

9. Kor, P. P., Kwan, R. Y. C., Liu, J. Y., \& Lai, C. (2018). Knowledge, Practice, and Attitude of Nursing Home Staff Toward the Use of Physical Restraint: Have They Changed Over Time? Journal of Nursing Scholarship. doi: 10.1111/jnu.12415 
10. Liao, S. C., Chang, W. C., \& Li, C. P. (2015). The Effectiveness of Modified Restraint Glove in Critical Ill Patients. Journal of Health and Architecture, 2(1), 65-73. doi : 10.6299/JHA.2015.2.1.R7.65

11. Luk. E., Burry, L., Rezaie, S., Mehta, S., \& Rose, L. (2015). Critical care nurses' decisions regarding physical restraints in two Canadian ICUs: A prospective observational study.The Canadian Journal of Critical Care Nursing, 26(4), 16-22. doi:10.1111/j.14785153.2007.00209.x

12. Ni Lochlainn, M., Bowyer, R., \& Steves, C. (2018). Dietary protein and muscle in aging people: The potential role of the gut microbiome. Nutrients, 10(7), 929. doi:10.3390/nu10070929

13. Raguan, B., Wolfovitz, E., \& Gil, E. (2015). Use of Physical Restraints in a General Hospital: a Cross-Sectional Observational Study. Isr Med Assoc J, 17(10), 633-638. doi:10.1016/S1878-7649(14)70194-9

14. Stinson, K. J. (2016). Nurses' Attitudes, Clinical Experience, and Practice Issues With Use of Physical Restraints in Critical Care Units. American Journal of Critical Care, 25(1), 21-26. doi: 10.4037/ajcc2016428

15. Word Health Organization,WHO. (2018). Ageing and Life Course. Retrieved on August 10, 2018, from: http://www.who.int/ageing/en/

16. Word Health Organization,WHO. (2018). Ageing and Life CourseLong-term-care systems. Retrieved on August 10, 2018, from: http://www.who.int/ageing/long-term-care/en/ 